\title{
ESTUDO DO USO DE COMBUSTÍVEIS ALTERNATIVOS NO FORNO DA INDÚSTRIA DO CIMENTO
}

\author{
B. L. VÉRAS ${ }^{1}$, J. I. SOLLETI ${ }^{1}$, E.M.CARNEIRO FILHO ${ }^{2}$, W.U.LEITE ${ }^{1}$, T.A.F. ROCHA ${ }^{1}$ \\ ${ }^{1}$ Universidade Federal de Alagoas, Curso de Engenharia Química \\ ${ }^{2}$ Universidade Federal de Sergipe, Departamento de Engenharia Química \\ E-mail para contato: veras.bruna@hotmail.com
}

\begin{abstract}
RESUMO - O cimento é um dos produtos mais utilizados pela humanidade nos últimos tempos, e o setor industriário responsável pela produção do mesmo visa, como toda indústria, a otimização do processo para a obtenção do produto afim de alcançar redução no custo de produção. Partindo deste princípio, este trabalho avalia, através de meio computacional, o uso de resíduos, industrial (coque de petróleo) e não industrial (pneu usado), como combustíveis alternativos para o forno de produção de clínquer, principal componente do cimento. Por meio do software Gams, gerou-se um programa que indica o melhor combustível a ser utilizado, tendo como comparativo o carvão mineral que é convencionalmente utilizado. Tal ferramenta também estabelece a composição ideal de matéria-prima e combustível para obtenção do clínquer.
\end{abstract}

\section{INTRODUÇÃOO}

O cimento é um material utilizado na construção civil e seu uso pode ser justificado por algumas características como durabilidade, versatilidade e resistência. A indústria de cimento é um dos setores que vem crescendo nos últimos anos, movimentando bilhões de dólares anualmente em todo o mundo (FRANCO et. al., 2001). O cimento portland é o tipo de cimento mais utilizado na construção civil. Foi descoberto em 1830 pelo inglês Joseph Aspdin (SNIC, 2003).

$\mathrm{Na}$ indústria do cimento, a otimização do processo é importante pois diminui custos e impactos ambientais mantendo a qualidade do produto, estes fatores podem ser estudados em vários pontos do processo, entre eles a formação do clínquer no forno. O clínquer é o principal componente do cimento Portland e lhe confere resistência mecânica após hidratação. (MONTEIRO; MAINIER, 2008).

A queima do clínquer é uma das partes do processo que mais tem influência na qualidade do produto, no custo de produção e nas emissões de poluentes. Nesta etapa a matéria-prima é introduzida no forno de cimento e é então sujeita a tratamentos térmicos, entre eles está a sinterização, também denominada como clinquerização, onde ocorre a 
formação do clínquer à temperaturas em torno de $1500^{\circ} \mathrm{C}$, para isso se é exigido uma grande quantidade de combustível (CEMBUREAU, 1999).

A escolha do combustível para queima do clínquer é algo de suma importância e tem de ser feita de forma criteriosa. Este tem influência direta ou indireta, podendo ser: na qualidade do clínquer, através da composição química do mesmo; na temperatura do forno; no meio ambiente, através da emissão de poluentes; na saúde humana, através da emissão de metais pesados; no custo de fabricação do clínquer, levando em consideração os custos do combustível como também o pré-tratamento do mesmo antes de ser lançado ao forno; entre outros (CARPIO, 2005). Levando em consideração a influência do combustível no processo de produção, tem-se estudado cada vez mais a utilização de combustíveis alternativos além dos mais usuais como o coque de petróleo e o gás natural.

A maioria das indústrias, no processo de escolha de um novo combustível, faz testes de queima, e, assim, analisam a viabilidade do mesmo. O uso de um modelo matemático, implementado computacionalmente, pode auxiliar as indústrias no estudo de novos combustíveis, aumentando a eficiência da pesquisa (CARPIO, 2005).

$\mathrm{Na}$ engenharia química, o uso de modelos matemáticos de otimização tem sido valorizado cada vez mais, especialmente na engenharia de sistemas de processo. No meio industrial, onde a competitividade é acirrada, visa-se sempre melhorar seus processos de produção a fim de minimizar custos para maximizar lucro, garantindo também um produto de excelência e mais acessível. Portanto, a otimização se tornou uma tecnologia importante que ajuda a indústria química para se manterem competitivas (CASTILHO,2007).

O GAMS é um software que foi desenvolvido para solucionar problemas de otimização. O manuseio deste software é de fácil compreensão, permitindo ao usuário poder alterar a formulação do problema em estudo de forma rápida e simples, trocar o método numérico de resolução implementado. O GAMS pode ser utilizado em grandes aplicações de modelagem em escala, e possibilita o desenvolvimento de grandes modelos sustentáveis que podem ser adaptados rapidamente a novas situações (ROSENTHAL,2008).

\section{METODOLOGIA}

O problema propõe a redução do custo de produção por meio da escolha do combustível utilizado. Sendo assim, determinou-se Custo como a variável a ser otimizada. Para tal utilizou-se a função não-linear adotada por Carpio (2005):

$$
\text { Custo }=\sum_{i} x_{i} w_{i}+w_{e e} A e^{B S}
$$

onde: $\mathrm{x}_{\mathrm{i}}=$ Quantidade da matéria prima e combustível $(\mathrm{t}) ; \mathrm{w}_{\mathrm{i}}=$ preço da matérias prima e combustível por tonelada $(\mathrm{R} \$) ; \mathrm{w}_{\mathrm{ee}}=$ preço da energia elétrica $(\mathrm{R} \$ / \mathrm{kWh}) ; \mathrm{A}=$ coeficiente em função do Módulo de Silica; $B$ = Coeficiente em função do Módulo de Sílica; $\mathrm{S}=$ Superfície específica do cimento. 
Para minimização da função custo, montou-se um sistema de equações que representam as seguintes restrições:

- Composição química do clínquer;

- Emissão de poluentes;

- Calor específico no forno de cimento.

Os combustíveis avaliados neste trabalho são: Coque de Petróleo, Carvão Mineral, e Pneu usado. E para formulação das equações usou-se os dados presentes nas Tabelas 1, 2, 3, e 4:

Tabela 1 - Composição Química das matérias-primas do cru (\% em peso)

\begin{tabular}{|l|c|c|c|c|c|c|c|c|c|}
\hline Material & & $\mathbf{C a O}$ & $\mathbf{S i O}_{\mathbf{2}}$ & $\mathbf{A l}_{\mathbf{2}} \mathbf{O}_{\mathbf{3}}$ & $\mathbf{F e}_{\mathbf{2}} \mathbf{O}_{\mathbf{3}}$ & $\mathbf{M g O}$ & $\mathbf{S O}_{\mathbf{3}}$ & $\mathbf{N a}_{\mathbf{2}} \mathbf{O}$ & $\mathbf{K}_{\mathbf{2}} \mathbf{O}$ \\
\hline Calcário & $\mathrm{X}_{1}$ & 50,60 & 5,04 & 1,19 & 0,67 & 0,78 & 0,1 & 0,1 & 0,3 \\
\hline Argila & $\mathrm{X}_{2}$ & 1,23 & 61,62 & 16,59 & 9,01 & - & 0,3 & 0,3 & 5,0 \\
\hline Areia & $\mathrm{X}_{3}$ & 1,13 & 93,00 & 2,87 & 1,20 & 0,1 & 0,5 & 0,5 & 1 \\
\hline Minério de Ferro & $\mathrm{X}_{4}$ & 0,71 & 7,60 & 1,13 & 82,97 & - & - & - & - \\
\hline
\end{tabular}

Tabela 2 - Composição parcial dos combustíveis primários e alternativos utilizados

\begin{tabular}{|l|c|c|c|}
\hline \multirow{2}{*}{ Componentes } & $\begin{array}{c}\text { Carvão Mineral } \\
\text { \% em peso }\end{array}$ & $\begin{array}{c}\text { Coque de Petróleo } \\
\text { \% em peso }\end{array}$ & $\begin{array}{c}\text { Pneus usados } \\
\text { \% em peso }\end{array}$ \\
\cline { 2 - 4 } & $\mathrm{X}_{5}$ & $\mathrm{X}_{6}$ & $\mathrm{X}_{7}$ \\
\hline $\mathrm{S}$ & 4,6 & $0,5-7,0$ & 1,23 \\
\hline $\mathrm{CaO}$ & 1,03 & - & 0,93 \\
\hline $\mathrm{SiO}_{2}$ & 9,32 & - & 1,93 \\
\hline $\mathrm{Al}_{2} \mathrm{O}_{3}$ & 5,08 & - & 0,79 \\
\hline $\mathrm{Fe}_{2} \mathrm{O}_{3}$ & 7,21 & - & 0,13 \\
\hline $\mathrm{MgO}$ & 0,44 & - & 0,12 \\
\hline $\mathrm{Zinco}$ & 0,04 & $85 \mathrm{ppm}$ & - \\
\hline $\mathrm{Cromo}$ & 0,008 & $23 \mathrm{ppm}$ & 0,0097 \\
\hline Vanádio & 0,0648 & $130-2300 \mathrm{ppm}$ & - \\
\hline $\begin{array}{l}\text { Poder Calorífico } \\
\text { Inferior (KJ/Kg) }\end{array}$ & 25392 & $32447-36425$ & 32100 \\
\hline
\end{tabular}

Tabela 3 - Limites dos componentes do Cimento e superfície esférica

\begin{tabular}{|l|c|c|}
\hline Componente & $\begin{array}{c}\text { Conteúdo } \\
\text { (\% em peso) }\end{array}$ & $\begin{array}{c}\text { Superfície } \\
\text { Mínima }\end{array}$ \\
\hline
\end{tabular}




\begin{tabular}{|l|c|c|c|}
\hline & Mín & Máx & $\mathbf{( \mathbf { c m } ^ { 2 } / \mathbf { g } )}$ \\
\hline Clínquer & 65 & 75 & 3300 \\
\hline Pozolana Natural & 5 & 20 & 5500 \\
\hline Escória de Alto Forno & 10 & 20 & 2700 \\
\hline Cinzas Volantes & 10 & 20 & 6000 \\
\hline
\end{tabular}

Tabela 4 - Composição química mineralógica parcial do cimento

\begin{tabular}{|l|c|}
\hline Componente & \% em peso \\
\hline $\mathrm{SiO}_{2}$ & $19,71-34,25$ \\
\hline $\mathrm{Al}_{2} \mathrm{O}_{3}$ & $3,76-6,78$ \\
\hline $\mathrm{CaO}$ & $63,76-70,14$ \\
\hline $\mathrm{Fe}_{2} \mathrm{O}_{3}$ & $1,29-4,64$ \\
\hline $\mathrm{MgO}$ & $0,00-4,51$ \\
\hline $\mathrm{SO}_{3}$ & $0,20-2,07$ \\
\hline $\mathrm{K}_{2} \mathrm{O}$ & $0,31-1,76$ \\
\hline $\mathrm{Na}_{2} \mathrm{O}$ & $0,03-0,33$ \\
\hline
\end{tabular}

O problema não-linear foi implementado no software Gams, e os resultados obtidos serão demonstrados em tabela. Segue o problema implementado na Figura1:

\section{RESULTADOS}

Para resolução do problema não-linear usou-se o método de resolução MINOS presente no software Gams. Obteve-se então os dados apresentados na Tabela 5 referentes à produção de $1000 \mathrm{Kg}$ de clínquer:

Tabela 5. Composição do material introduzido no forno para produção de cimento obtida no programa em estudo

\begin{tabular}{|l|c|c|}
\hline Componente & Material & Quantidade (Kg) \\
\hline \multirow{4}{*}{ Matéria-prima } & Calcário & 643,0 \\
\cline { 2 - 3 } & Argila & 194,0 \\
\cline { 2 - 3 } & Areia & 48,0 \\
\cline { 2 - 3 } & Minério de Ferro & 11,0 \\
\hline \multirow{3}{*}{ Combustível } & Carvão Mineral & 0,0 \\
\cline { 2 - 3 } & Coque de Petróleo & 105,0 \\
\cline { 2 - 3 } & Pneus usados & 0,0 \\
\hline
\end{tabular}

Segundo os dados da Tabela 5, observou-se que o programa nos forneceu o Coque de Petróleo como o melhor combustível a ser utilizado para produção de clínquer, isto quando comparado aos demais combustíveis analisados, carvão mineral e pneu usado. As 


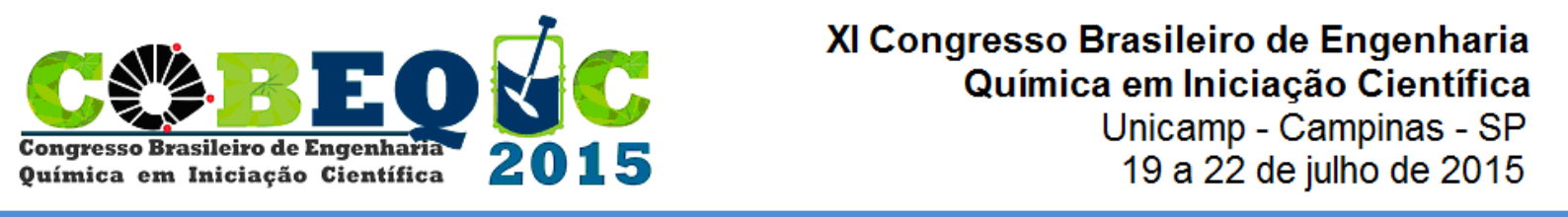

composições de matéria-prima e do combustível apresentadas seguem as restrições impostas pelo problema, nos dando também a composição ótima para produção do mesmo. Quanto ao custo de produção, o programa simulou um gasto de $\mathrm{R} \$ 145,00 / \mathrm{t}$ de clínquer produzido. Vale ressaltar que os valores de custo atribuídos à matéria-prima são fictícios devido à dificuldade de encontrar valores reais e atualizados. Mesmo assim, o resultado encontrado valida o programa tendo em vista que o custo de matéria-prima por tonelada será constante independente do combustível utilizado.

\section{CONCLUSÃO}

O coque de petróleo apresentou-se como melhor opção de combustível a ser utilizado para produção de cimento em forno rotativo visando a redução de custo do processo e tendo como comparativo o carvão mineral e pneu usado. O programa gerado para resolução do problema em questão também apresentou a composição ideal para obtenção do clínquer. Logo, além de obter-se uma diminuição no custo de produção, tem-se também a garantia da qualidade do produto. Sendo assim, o Gams mostrou-se uma ferramenta ideal para resolução de problemas de mistura, tal como o estudado neste trabalho.

\section{NOMENCLATURA}

Tabela 6 - Nomenclatura das fórmulas moleculares

\begin{tabular}{|l|c|}
\hline Símbolo & Nomenclatura \\
\hline $\mathrm{Al}_{2} \mathrm{O}_{3}$ & Óxido de Alumina \\
\hline $\mathrm{CaO}$ & Óxido de Cálcio \\
\hline $\mathrm{Fe}_{2} \mathrm{O}_{3}$ & Óxido de Ferro \\
\hline $\mathrm{K}_{2} \mathrm{O}$ & Óxido de Potássio \\
\hline $\mathrm{MgO}$ & Óxido de Magnésio \\
\hline $\mathrm{Na}_{2} \mathrm{O}$ & Óxido de Sódio \\
\hline $\mathrm{SO}_{3}$ & Trióxido de Enxofre \\
\hline $\mathrm{SiO}_{2}$ & Óxido de Silício \\
\hline
\end{tabular}

\section{REFERÊNCIAS}

CARPIO, R. C. Otimização no Co-processamento de Resíduos na Indústria do Cimento, envolvendo Custos, Qualidade e Impacto Ambiental. 2005. 194 f. Tese (Doutorado) Curso de Engenharia Mecânica, Instituto de Engenharia Mecânica, Universidade Federal de Itajubá, Itajubá, 2005.

CASTILHO, E. Process Optimization - A Statistical Approach. Pennsylvania: Springer, 2007.

CEMBUREAU. Best Available Techniques for the Cement Industry. The European Cement Association, 1999. Disponível em: . Acesso em: 16/12/214. 
FRANCO JR., J. de O; KORN, M. G. A.; COSTA, A. C. S; SANTOS JR., A. de F. Alternativas Analíticas para Determinação de Ferro e Titânio em Cimento Portland. Química Nova, Salvador, v. 24, n. 2, 2001. Disponível em: < http://quimicanova.sbq.org.br/>. Acesso em: 16/12/2014.

MONTEIRO, L. P. C.; MAINIER, F. B. Queima de Pneus Inservíveis em Fornos de Clínquer. Engevista, Rio de Janeiro, v. 10, n. 1, p.52-58, Jun. 2008.

ROSENTHAL, E. R. GAMS - A User's Guide. GAMS Development Corporation, Washington, DC, USA, 2008.

SINDICATO NACIONAL DA INDÚSTRIA DO CIMENTO (SNIC). SNIC 50 anos: História do cimento no Brasil. Rio de janeiro, 2003. 